\title{
Archaean basalts record evidence of lithospheric extension prior to cratonisation
}

\author{
MARTHE KLÖCKING ${ }^{1,2}$, KAROL CZARNOTA ${ }^{3}$, IAN H. \\ CAMPBELL $^{1}$, HUGH SMITHIES ${ }^{4}$, DAVID C. CHAMPION ${ }^{3}$ \\ AND D. RHODRI DAVIES ${ }^{1}$ \\ ${ }^{1}$ Australian National University \\ ${ }^{2}$ Georg-August-Universität \\ ${ }^{3}$ Geoscience Australia \\ ${ }^{4}$ Geological Survey of Western Australia \\ Presenting Author: marthe.kloecking@cantab.net
}

The dynamics of Earth's early mantle and the origins of plate tectonics remain a topic of speculation and debate. Proposed hypotheses range from a stagnant-lid Earth, to plume dominated processes to protracted slow stretching and depletion via decompression melting. Here, we seek to shed light on this issue by estimating temperatures and depths of melt generation in the Archaean mantle using a new geochemical data compilation of mafic igneous rocks from Australia. We combine these results with stratigraphic and geodynamic constraints to better resolve Archaean upper mantle dynamics.

Primitive volcanic rocks can preserve signatures of the melting processes in the mantle: depth and temperature of melting are recorded in magma major and trace element chemistry. We have collated a database of mafic volcanic samples from the Archaean Yilgarn craton in Western Australia. In order to identify those samples most representative of melting conditions in the convecting mantle, the data were screened to minimise the effects of crystal fractionation and assimilation of crustal or cumulate material ( $9 \mathrm{wt} \%<\mathrm{MgO}<15 \mathrm{wt} \%$; no $\mathrm{Eu}$ anomalies, no positive $\mathrm{Pb}$ anomalies; $\mathrm{Nb} / \mathrm{U}>30$ ). We further correct these screened compositions for olivine fractionation. This screened dataset predominantly comprises tholeiitic basalts in the Kalgoorlie terrane that erupted prior to the main komatiite sequence and the felsic magmas that make up the bulk of the cratonic crust. The mafic compositions investigated here therefore represent melting conditions before the onset of cratonisation.

The screened data display depleted, MORB-like rare earth element patterns with no evidence of a garnet signature. Forward and inverse modelling of these compositions, assuming a primitive mantle source, predicts melting at depths as shallow as $\sim 40 \mathrm{~km}$ and mantle potential temperatures elevated by $\sim 100{ }^{\circ} \mathrm{C}$ compared to present-day ambient mantle. These results are consistent with decompression melting of a slightly hotter Archaean mantle, induced by moderate extension of the preexisting lithospheric lid. We speculate that this extension could be caused by the stress field above a rising mantle plume that subsequently triggered komatiite melting and cratonisation. 